\title{
Role of male-female interaction in regulating reproduction in sheep and goats
}

\author{
S. W. Walkden-Brown ${ }^{1}$, G. B. Martin ${ }^{2}$ and B. J. Restall ${ }^{3}$ \\ ${ }^{1}$ Aninial Science, School of Rural Science and Natural Resources, University of \\ New England, Armidale, NSW 2351, Australia; ${ }^{2}$ Faculty of Agriculture (Aninal Science), \\ The University of Western Australia, Nedlands 6907, Australia; ${ }^{3}$ Capratech Consulting, \\ 822 Teven Rd., Teven, NSW 2478 Australia.
}

\begin{abstract}
The induction of synchronous ovulatory activity in anovulatory sheep and goats after the introduction of males, the 'male effect', has probably been used to advantage since these species were domesticated and the underlying physiological and behavioural mechanisms have been progressively elucidated over the past 50 years. Less well understood is the analogous effect of oestrous females on males. This review examines the nature and importance of these male-female interactions in sheep and goats, and describes the most important internal and external factors influencing the reproductive outcomes of such interactions. It is proposed that the male and female effects are both components of a self-reinforcing cycle of stimulation that, under ideal conditions, culminates in the synchronous very rapid onset (within days) of fertile reproductive activity. However, precisely because of the speed of this response, it is suggested that mechanisms have evolved to limit its efficacy, and thus prevent conception at inappropriate times. The complexity of these factors and the interactions between them are highlighted, and a broad conceptual framework for understanding them is proposed based upon an appreciation of variation in both the responsiveness of the target animal and the quality of the signal from the signalling animal.
\end{abstract}

\section{Introduction}

In some production systems for small ruminants, reproduction is strictly controlled by isolating females from males apart from a brief mating period, whereas in other systems, males and females are not physically segregated at all. Irrespective of the mating system used, it is clear that there are times when male-female interaction triggers a cascade of physiological events culminating in successful conception, often highly synchronous, times when no response is evident, and times when an intermediate response is observed. In this review the nature of male-female interactions in two species, sheep and goats, is examined and the most important factors influencing the reproductive outcome of such interactions are described. The complexity of these factors and their interactions is highlighted, and a broad conceptual framework for understanding them is proposed. By virtue of its breadth, the review will not cover all of the detailed physiology underlying the responses.

\section{Nature and Importance of Male-Female Interaction in Sheep and Goats}

\section{An evolutionary perspective}

Reproduction in wild sheep and goats is characterized by long periods of segregation between mature males and females while the females are anoestrous (before puberty, during gestation and lactation, during photoperiodic or nutritional anoestrus) interspersed with shorter periods during 
which the male and female herds combine, often accompanied by intense sexual activity (Shackelton and Shank, 1984). Periodic reuniting of the sexes appears to have two important roles in these animals. The first is to initiate breeding activity by inducing females to make the transition from the anoestrous to the oestrous state earlier than in the absence of males, in which case other environmental and physiological factors determine the timing. The second is to ensure synchrony of the female cycles, primarily to enable synchronous parturition as a defence mechanism against predators. This 'fine tuning' of the timing of the end of anoestrus by social cues remains strongly evident in domestic breeds, although the extent to which it can be used to advance the spontaneous onset of ferfile oestrus varies greatly among breeds and species.

\section{Female responses to male introduction - the 'male effect'}

The induction of synchronous ovulatory activity in anovulatory females after the introduction of males, the so-called 'male effect', has been widely documented for sheep and goats (reviews: Martin et al., 1986; Chemineau, 1987). In responsive ewes and does, the primary response to the male stimulus is an immediate increase in LH pulse frequency (Martin et al., 1980; Chemineau et al., 1986a), reflecting increased pulsatile secretion of GnRH (Hamada et al., 1996). The secretion of LH increases within minutes and, in fully responsive ewes, leads to a preovulatory surge of LH 6-52 h after introduction of the male, followed by ovulation 23-24 h later (Oldham $e^{2}$ al,, 1978 ). In ewes, this initial ovulation is invariably 'silent' (that is, not accompanied by oestrus) and may be followed by a short luteal phase and a second silent ovulation 6-7 days later or a normal luteal phase and ovulation with oestrus about 18 days later, or both in sequence. In each case, if the response is maintained, subsequent ovulations follow a luteal phase of normal duration and are associated with oestrus. The situation in responsive female goats differs in that a variable number of does exhibit oestrus at the first induced ovulation, 2-3 days after introduction of the male, and the majority go on to have a short luteal phase followed by a second ovulation 5-7 days later, invariably accompanied by oestrus. As in the sheep, subsequent ovulations follow a normal luteal phase and are accompanied by oestrus. Administration of progesterone or progestagens to ewes and does just before introduction of the male prevents the abnormal luteal phases and can be used to ensure oestrus and fertility at the first or second induced ovulation (Cognié et al., 1982; Chemineau, 1985).

\section{Male responses to exposure to females - the 'female effect'}

In both the ram and goat buck, exposure of males to oestrous females may stimulate an immediate increase in LH secretion, analogous to the male effect in females (Sanford et al., 1974; Howland et al., 1985). Consequently, this has been termed the 'female effect' (Fig. 1). Testosterone secretion is stimulated by the increase in LH secretion (Sanford et al, 1974; Schanbacher et al., 1987; Walkden-Brown et al., 1994a) and there are also increases in plasma concentrations of FSH, cortisol and prolactin (Howland et al., 1985; Gonzalez et al., 1988a,b; Borg et al., 1992). Increased secretion of gonadotrophins and androgen is associated with courtship behaviour, whereas increased concentrations of cortisol and prolactin are associated with mounting and intromission (Borg et al., 1992). Increases in cortisol and prolactin are also induced by electroejaculation in the absence of females (Martin et al., 1984) indicating that they represent a non-specific stress response. Homosexual rams fail to exhibit an LH or testosterone response to oestrous ewes (Perkins and Fitzgerald, 1992).

The functional significance of the female effect has yet to be determined. It is possible that the increase in testosterone secretion leads to behavioural changes that improve the success of mating although reproductive behaviour does not appear to be acutely sensitive to testosterone concentrations (Matther and Braden, 1975). However, exposure to oestrous females clearly enhances the ability of rams and goat bucks to induce ovulation in seasonally anovulatory females (Knight, 1985; Walkden-Brown et al., 1993a) suggesting that the female effect is one component of a selfreinforcing cycle of stimulation that may be initiated by either sex. 


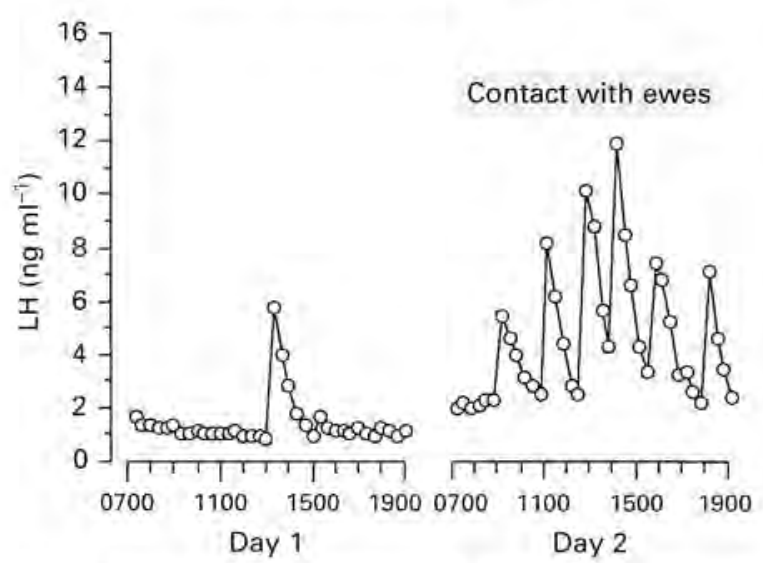

Fig. 1. Representative profile of peripheral LH concentration in a mature Merino ram before and during exposure to oestrous ewes, Samples were collected at 20 min intervals for the same $12 \mathrm{~h}$ period on successive days with ewes placed in pens beside rams after the first blood sample on day 2. (From data of Walkden-Brown et al., 1993d)

\section{Signalling mechanisms - the male stimulus}

In sheep, the male effect involves a range of sex steroid-dependent stimuli. Long-term castrates (wethers) are ineffective unless they have been treated with androgen or oestrogen and androgentreated ovariectomized ewes can also induce ovulation (Fulkerson et al., 1981; Signoret et al., 1982). The odour of fleece, but not urine, may induce a full ovulatory response (Knight and Lynch, 1980; Knight et al., 1983a), and anosmic ewes exhibit a depressed ovulatory response to rams (Morgan et al., 1972), but olfactory cues are not the only male stimulus responsible. In a series of experiments, Pearce and Oldham (1988) showed that rams in full contact with ewes invariably induced a greater ovulatory response than rams separated from ewes by clear or opaque fences. They concluded that tactile stimuli were important in the male effect. Anosmic ewes also exhibit a normal LH response to rams, but not rams fleece, suggesting that other cues are involved (Cohen-Tannoudji et al., 1986).

The situation appears to be similar in goats. Bucks in direct contact with does induce a greater ovulatory response than those separated by a fence, a narrow passage or a solid partition (Shelton, 1980; Chemineau, 1987). Exposing does to buck fleece alone may induce a partial ovulatory response (Shelton 1980; Claus et al., 1990; Walkden-Brown et al., 1993b) but urine odours do not appear to be important in mediating the effect (Walkden-Brown et al, 1993b). Anosmia had no effect on the proportion of does exhibiting an increase in $\mathrm{LH}$ secretion in response to introduction of a buck, but it reduced by half the number of does ovulating in the study of Chemineau et al. (1986b). These observations suggest that the male stimulus is multi-sensory, possibly involving olfactory, visual, tactile and auditory cues and that, as in the sheep, the intensity of the male stimulus is important.

Considerable research effort has been expended on the olfactory component of the stimulus, encouraged by reports that the full ovulatory response of ewes is induced by olfactory cues from rams (Knight and Lynch, 1980; Knight et al, 1983a), and reports that goat bucks and extracts of buck hair are able to induce ovulation in seasonally anovulatory ewes, in some cases as effectively as rams. (Knight et al., 1983a; Birch et al., 1989), This interesting interspecies interaction led to suggestions that a pheromone common to both species is a necessary component of the multi-sensory complex needed to induce the male effect (see Martin et al., 1986 for discussion on the use of the term pheromone in this context). Despite some work on ram fleece (review; Signoret, 1991), most work on the isolation of a male pheromone in small ruminants has concentrated on the goat buck because of the pronounced buck odour associated with the seasonal rut in this species, and despite the dangers 


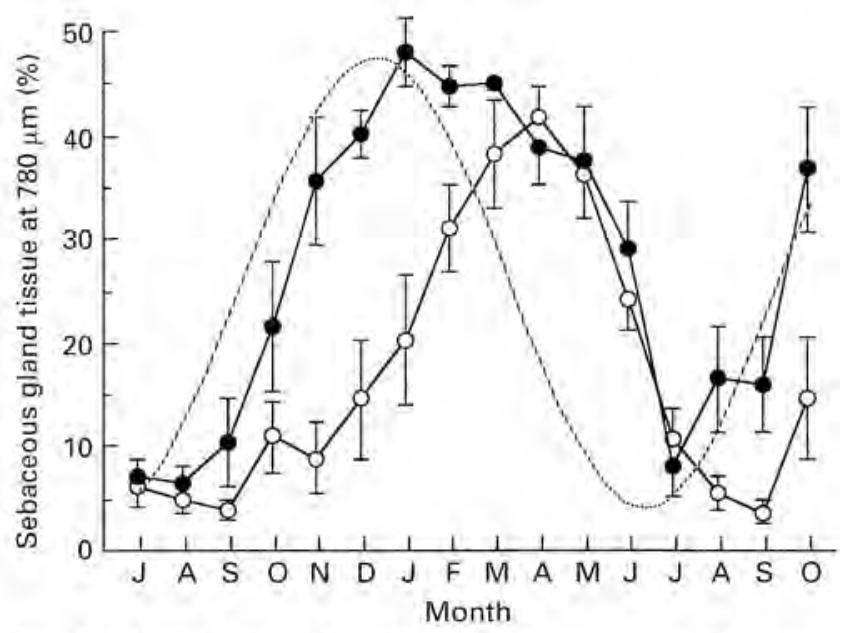

Fig. 2. Monthly means ( \pm SEM) for the percentage of sebaceous gland tissue at a skin depth of $780 \mu \mathrm{m}$ in samples taken from the occipital region of 3-year-old cashmere bucks fed diets of Low (O, $n=6$ ) or High (-, $n=6$ ) quality ad libitum under natural photoperiod at $29^{\circ} \mathrm{S}$ for 16 months. The dashed curve represents the annual curve of photoperiod (units not shown, range $10.3-14.0 \mathrm{~h}$ ). Note the season $\times$ nutrition interaction resulting in increased sebaceous gland activity during spring and summer. Adapted from Walkden-Brown et al. (1994b).

inherent in such a subjective and anthropomorphic hypothesis. The rutting odour of the goat has been shown to be a testis-dependent component of sebum that varies with the activity of sebaceous glands especially in the head and neck region (Jenkinson et al,, 1967; Walkden-Brown et al, 1994b; Hillbrick and Tucker, 1996). This variation is markedly influenced by both season and level of nutrition (Fig. 2). During the breeding season, the mean lipid content of buck fleece may reach $7 \%$ by weight (Hillbrick and Tucker, 1996). Both the fatty acid and non-acid components of buck hair extracts exhibit pheromonal activity, although 4-ethyloctanoic acid, which is largely responsible for the characteristic strong odour of bucks, does not (Birch et al., 1989; Claus et al., 1990). Taking these observations together, it is possible that a 'cocktail' of compounds is involved. This idea is supported by the demonstrable chemical complexity of the lipid fraction of buck hair (Jenkinson et al., 1967; Sugiyama et al., 1986) which contains up to 29 specific fatty acids that are not found in the fleece of wethers or does (Hillbrick et al., 1995).

\section{Signalling mechanisms - the female stimulus}

There is considerable evidence that olfactory cues from the female are important in sexual communication in sheep, particularly in the detection of oestrus. Rams are able to discriminate between urine from oestrous and non-oestrous ewes, primarily using the main olfactory system, rather than the vomeronasal olfactory system (Blissitt et al., 1990). However, non-oestrous ewes are able to induce LH and testosterone responses in rams, albeit to a lesser degree than oestrous ewes (Gonzalez et al., 1991a), and olfactory cues appear to play a minor role in inducing endocrine responses to either oestrous or non-oestrous ewes in males. Olfactory stimulation of rams with female urine, wool and vaginal secretions fails to induce, and surgical anosmia fails to abolish the LH and testosterone response of experienced rams to oestrous females (Gonzalez et al., 1991b). On 


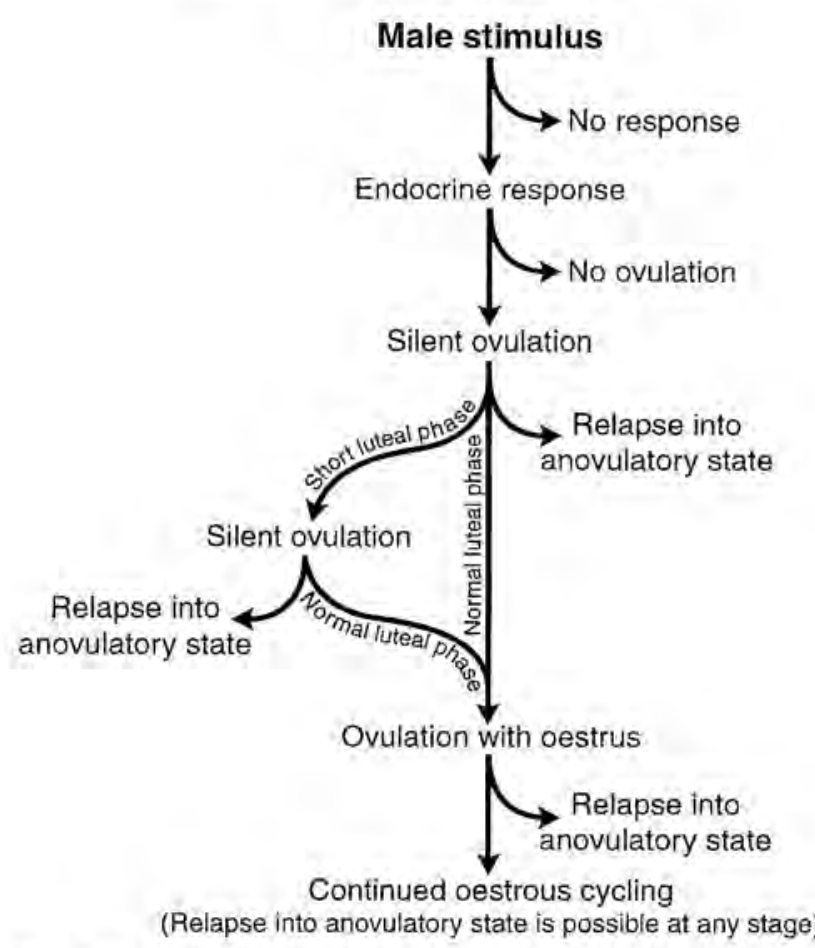

Fig. 3. The range of possible outcomes for an anovulatory ewe in response to a male stimulus. Note that the response can be terminated at any stage providing the ewe with protection against conception at an inappropriate time. Continuation of the response depends upon responsiveness of the ewe and continuation of the male stimulus. The situation in the goat is different in that many does exhibit oestrus at the first ovulation (though usually infertile) and almost all exhibit fertile oestrus at a second ovulation following a short luteal phase.

the basis of these data, olfactory cues are more important in mediating the 'male effect' than the 'female effect' and in both of these, olfactory cues form only part of a multi-sensory stimulus.

\section{Variation in response}

A key feature of male-female interaction in sheep and goats is variation in the response after contact with the other sex. This ranges from a failure to elicit any endocrine response to the stimulus, detection of an endocrine response without behavioural or other physiological sequelae, development of a significant physiological or behavioural response that is not sustained, through to a sustained transition from an infertile to a fertile state (Fig. 3). This variation in response may be due to either variation in responsiveness of the target animal or variation in the quality of the stimulus provided by the signalling animal.

Both of these factors appear to be important in determining the type of response obtained after male-female interaction, and both of them seem to be influenced by complex interactions between a number of internal and external environmental factors. This concept is illustrated in Fig. 4 and the major determinants of responsiveness and stimulus quality are discussed below.

Variation in target animal responsiveness. In females, variation in responsiveness to males is generally reported as differences in 'depth of anoestrus'. Although the term was originally used to 


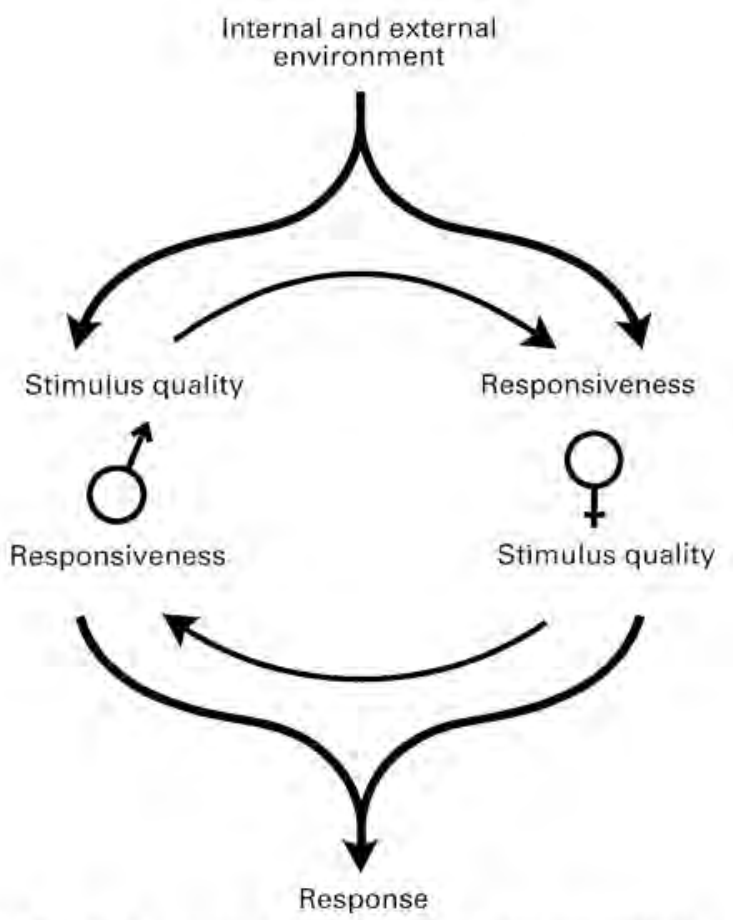

Fig. 4. A conceptual framework for considering male-female interaction. Internal and external factors influence responses by acting on responsiveness and stimulus quality in both sexes. Increases in one stimulate increases in the other in a self-reinforcing cycle that may be damped by environmental and physiological constraints.

describe variation in the extent of photoperiodic inhibition of reproduction in the ewe, its meaning has now been broadened to refer to the extent of inhibition of the reproductive axis in the female irrespective of cause (for example Martin et al., 1986; Chemineau, 1987). If the male effect in goats is used as an example, increasing depth of anoestrus seems to be associated with:

(1) Reductions in the proportion of does ovulating, or total failure to ovulate (Chemineau, 1987; Restall, 1992);

(2) Reductions in the proportion of does exhibiting oestrus at first ovulation (Chemineau, 1983; Walkden-Brown et al., 1993c);

(3) Increases in the proportion of responding does having a short luteal cycle after the first ovulation (Chemineau, 1983);

(4) Increases in the interval (up to a week) between introduction of the buck and the first ovulation (Chemineau 1983, 1987);

(5) Increases in the proportion of does returning to an anovulatory state after one or more ovulations (Chemineau et al., 1986a).

Indeed, the extent of responsiveness to the male effect has been used by Restall (1992) to partition the reproductive cycle of female goats into active, responsive and quiescent periods.

There is no universal measure of 'depth of anoestrus', but because the proportion of anovulatory ewes ovulating in response to introduction of the ram is positively associated with the proportion of ewes ovulating spontaneously in the flock before introduction of the male (Lindsay and Signoret, 
1980), either variable is a useful indicator of it. However while the 'depth of anoestrus' concept is a useful means of integrating all of the inhibitory influences on the reproductive axis into a single measure, it has two drawbacks. The first is that the term 'depth of anoestrus' is inappropriate to apply to males although the underlying concept applies in males as well as females. The second drawback is that measures of 'depth of anoestrus' based upon responses to male introduction confound true 'depth of anoestrus' in the female with variation in signal strength from the male and probably result in underestimation of the importance of the latter in explaining variation in responses. For these reasons less ambiguous terminology to describe the extent of responsiveness will be used in the remainder of the review.

Variation in the quality of the stimulus. The quality of the sexual stimulus appears to be a function of the intensity, duration and complexity of the sexual stimulus, with each influencing the type of response obtained. Thus, in both sheep and goats, the degree and type of separation from males influences the ovulatory response obtained (Shelton, 1980; Pearce and Oldham, 1988), and the continued presence of the male is required for maximum ovulatory response or persistence of the induced ovulatory activity (Signoret $e t$ al., 1982; Murtagh et al., 1984a). Similarly, the LH response to rams is sensitive to the continued presence of the male stimulus, with short-term stimulation $(<24 \mathrm{~h})$ failing to induce ovulation or maintain the increase in LH pulse frequency (Signoret et al., 1982; Cohen-Tannoudji and Signoret, 1987). The ovulatory response in both sheep and goats has been shown to vary with male libido; high libido males induce the greater response (Fig. 5; Signoret et al., 1982; Perkins and Fitzgerald, 1994). Anosmia presumably reduces the complexity of the stimulus received and this may explain the low ovulatory response of anosmic females to males, as observed in both species (Morgan et al., 1972; Chemineau et al., 1986b).

Less is known about the 'female effect', except that oestrous ewes elicit greater LH responses in rams than do non-oestrous ewes (Gonzalez et al., 1991a) suggesting a difference in stimulus quality. Direct contact between rams and ewes is also required to obtain the acute LH response, and separation by as little as $30 \mathrm{~cm}$ is sufficient to prevent it (Gonzalez et al., 1988a).

\section{Internal and External Determinants of Responsiveness and Stimulus Quality}

The ways that internal and external factors can modulate male-female interactions and responses are inherently complex because those factors often interact amongst themselves to influence the reproductive axis, they may have similar or different effects on the two sexes, and their actions may influence both the responsiveness to stimuli from the other sex and the quality of the stimulus provided for the other sex.

\section{Novelty of the stimulus}

Originally it was considered that about a month of separation between the sexes was required before an efficient 'male effect' could be obtained. However, subsequent work has shown that exposure to rams for $2-3 \mathrm{~h}$ has no effect on the responsiveness of ewes to re-exposure to rams as little as $24 \mathrm{~h}$ later (Cohen-Tannoudji and Signoret, 1987), and that the introduction of novel rams to ewes that are already in contact with rams will induce a high proportion of anovulatory ewes to ovulate (Pearce and Oldham, 1988; Cushwa et al., 1992). This finding suggests that the novelty of the male stimulus, rather than its presence or absence, is most important and implies that ewes become refractory to an unchanging male stimulus. This contention is supported by findings that ewes maintained continuously with rams exhibit a seasonal pattern of oestrous activity which is similar to that of isolated ewes, whereas ewes that are intermittently exposed to rams show a higher incidence of oestrus during the anoestrous period (Riches and Watson, 1954; Lishman, 1969). On the other hand, Notter (1989) found that anovulatory ewes in continuous association with rams were less responsive to introduction of a novel ram than were isolated ewes. He suggested that a novel ram stimulus cannot totally overcome the effects of refractoriness. In contrast to sheep, female goats do not appear to become refractory to continuous exposure to bucks, because does exhibit the same 


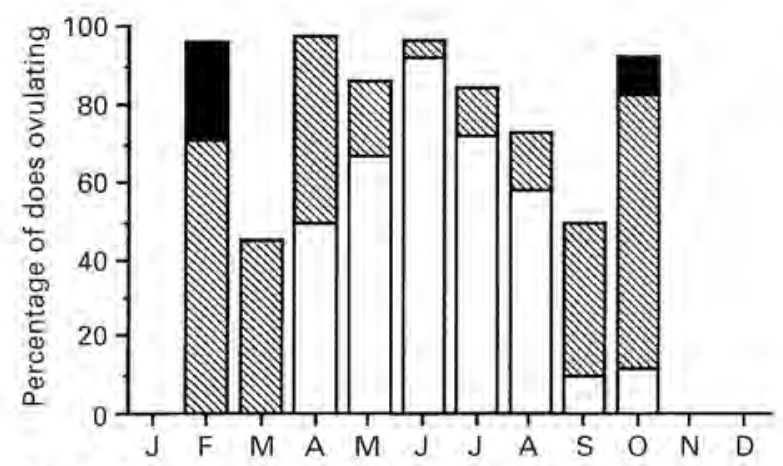

Fig. 5. Effect of varying the male stimulus on responses of Australian cashmere goats to the introduction of males. Data derived from Restall (1992) illustrate the proportion of does ovulating spontaneously $(\square)$ and ovulating 14 days after exposure to vasectomized males ( $\mathbb{N}$ ) throughout the year in a paddock (data adjusted to mid-point of each month). The data from Walkden-Brown et al. (1993c) (columns with solid section at the top) are from experiments carried out when does were unresponsive in Restall's experiment (February and October). They illustrate the ovulatory responses of seasonally anovulatory cashmere does 10 days after being exposed to normal $(\mathbb{N})$ or 'enhanced' (⿴) males in $100 \mathrm{~m}^{2}$ enclosures containing a buck and 10 does (threre replicates for each treatment). Bucks were 'enhanced' by improved nutrition or exposure to oestrous females before introduction. In the February experiment the 'enhanced' bucks were exposed to oestrous females for 2 days before introduction, whereas in the October experiment the 'enhanced' bucks had been on a high quality ad libitum diet for 16 months before introduction and had been exposed to vestrous females at intervals of 2 months. The high ovulatory response to normal bucks reported by WalkdenBrown et al. (1993c) suggests that enclosing males and females in a relatively confined space increases the response.

prolonged breeding season when they are in constant contact with bucks and when they are exposed to bucks intermittently throughout the year (Cameron and Batt, 1989; Restall, 1992). Under both conditions, the breeding season is initiated earlier and terminated later compared with that of does isolated from bucks.

Again, the roles of refractoriness and novelty for the 'female effect' are less well documented but they are likely to be just as important. Sanford et al. (1974) found that the LH and testosterone response of rams to oestrous ewes declined to basal values after about $12 \mathrm{~h}$, despite continued sexual activity, suggesting some refractoriness to the female stimulus. Thiery and Signoret (1978) found that male reproductive behaviour declined rapidly within $5 \mathrm{~min}$ of the introduction of an oestrous ewe. Introduction of a new ewe, but not re-introduction of the same ewe, induced reproductive behaviours that were not different from those induced by the initial introduction.

\section{Requirement for prior sexual experience}

Prior sexual contact with males does not appear to be an important requirement for the male effect, and ovulatory responses are evident in many experiments using maiden females with limited 
post-weaning contact with males. However, Murtagh et al. (1984b) showed that exposing 11-monthold maiden ewes to rams improved their responsiveness to introduction to a ram 4 months later, albeit by a small amount. In goats, Walkden-Brown et al. (1993b) found that the ovulatory response to introduction to a buck in 30-month-old does was the same whether they had been isolated from males since weaning at 4 months of age, or had been exposed to vasectomized bucks for 10 days a year earlier.

The role of sexual experience in the female effect appears to be more important because sexually naive rams exhibit a smaller response in $\mathrm{LH}$ and testosterone secretion after exposure to females than do experienced males (Gonzalez et al, 1991a; Borg et al., 1992). Naive rams also show similar responses to both oestrous or anoestrous ewes, whereas experienced rams show a much greater response to oestrous ewes, suggesting a greater ability to detect oestrus (Gonzalez et al., 1991a). These variations in endocrine response may reflect differences in sexual activity (Gonzalez et al., 1991a; Borg et al., 1992; Perkins and Fitzgerald, 1992), although other studies have shown a lack of association between sexual activity and endocrine response (Gonzalez et al, 1988a,b).

\section{Effect of recent sexual stimulation}

Exposing rams (Knight, 1985) or goat bucks (Walkden-Brown et al., 1993a) to oestrous females, shortly before or during introduction to anovulatory females, increases the magnitude of the ovulatory response obtained. As discussed above, this is probably a major function of the 'female effect' in the reproductive strategy of the species. In sheep this mechanism probably explains reports that oestrous females induce ovulatory activity in anovulatory females, because direct female-female stimulation does not appear to be responsible (Knight, 1985). In contrast, goat does in oestrus are able to induce ovulation in anovulatory does both directly or via enhancement of the male effect (Walkden-Brown et al., 1993a; Restall et al., 1995).

\section{Stage of reproductive cycle}

The reproductive consequences of the male effect are greatest during anoestrus, although there is evidence that introduction of the male can induce a degree of synchronization in cyclic Creole goats (Chemineau, 1983). One mechanism for this may be a shortening of the follicular phase which has been reported after introduction of the male to cyclic ewes (Martin et al., 1986). Whether the introduction of males can influence the duration of the luteal phase of the oestrous cycle has not been clearly established. In acyclic females, introduction of the male advances the onset of puberty and advances the end of post-partum and seasonal anoestrus (see for example Amoah and Bryant, 1984; Geytenbeek et al., 1984; Martin and Scaramuzzi, 1983). Effects on pubertal advancement are constrained by the maturational development of the animal and the photoperiodic environment, but there is little doubt that in many controlled breeding situations involving seasonal breeds, the initial ovulation and oestrus in pubertal ewes and does is triggered by the introduction of rams and bucks. In the case of post-partum anoestrus, Geytenbeek et al. (1984) found that the ovulatory responses to males increased with time after parturition in autumn-lambing Merinos, but there was no effect on the timing of the first post-partum oestrus. However, responses are strongly influenced by both the time of year and the nutritional status of the ewes with poor nutritional status able to inhibit raminduced oestrus (but not ovulation) and facilitate the cessation of male-induced oestrous cycles (Wright et al., 1990).

\section{Photoperiod}

Photoperiod is undoubtedly the most important single regulator of reproductive activity in sheep and goats worldwide and is the basis of most of the 'seasonal breeding' observed in these species (for reviews see: Ortavant et al., 1988; Walkden-Brown and Restall, 1996). When considering the effects of photoperiod on male-female interaction the following concepts are important: 
(1) Photoperiod acts by selective inhibition of the reproductive axis at various times of the year, to ensure the birth and rearing of the young at the most favourable time of year. Generally speaking, inhibition is maximal during periods of increasing or long daylength (late winter through early summer).

(2) Responsiveness to the effects of photoperiod varies widely and is heritable. This is the basis of breed variation in seasonality. For this reason the effects of photoperiod must be considered both in terms of the current (and preceding) photoperiodic milieu and the photoresponsiveness of the breed in question.

(3) Within a given breed, photoperiodic inhibition of reproduction in females is greater than in males, probably because the adverse consequences of conception at an inappropriate time are much greater for females than for males. Thus, while long periods of seasonal anovulation and anoestrus are common in females, total cessation of sperm production is rare in males. Similarly, in photoresponsive breeds, testicular growth generally commences during increasing daylength in spring-summer and testicular size peaks in late summer-early autumn, well before the peak in spontaneous ovulatory activity in females in late autumn or early winter (Ortavant et al., 1988). However, in practice, male-female interaction ensures that most sheep and goats mate at the peak of the male cycle and early in the female cycle of responsiveness.

(4) The effects of photoperiod interact with other environmental and physiological cues to regulate the timing and magnitude of most reproductive variables and should not be considered in isolation.

Photoperiod and the male effect. Photoperiod is a major cause of variation in the degree of female responsiveness to males, whether it be at the pubertal, post-partum or seasonal transitions from anoestrus. In breeds exhibiting only moderate seasonality such as the Merino sheep and Creole goats, introduction of the male may induce an ovulatory response at any time of the year, although responses will vary with the extent of photoperiodic inhibition (Lindsay and Signoret, 1980; Chemineau, 1983). On the other hand, in breeds that are more strongly seasonal, the male effect may advance the onset of the normal breeding season by as little as a few weeks (Martin and Scaramuzzi, 1983; Chemineau, 1987). Importantly, the limitation on the usefulness of the male effect that is imposed by photoperiodic inhibition of female responsiveness might be overcome under experimental conditions by measures that increase the quality of the male stimulus. For example, in Australian cashmere goats in spring and summer, the ovulatory response to introduction of a buck is low or absent under normal paddock conditions (Cameron and Batt, 1989; Restall, 1992), whereas joining males and females in small groups in small enclosures, under experimental conditions that possibly impose a greater degree of contact between them, induces ovulatory responses in a high proportion of does (Fig. 5). Similarly Chemineau et al. (1986a) obtained full ovulatory responses in the markedly seasonal Saanen goat breed during deep anoestrus in late spring-early summer by using androgenized females and bucks treated with a light-melatonin regimen. From these observations, the quality of the male stimulus is an important contributor to the failure of the male effect during seasonal anoestrus, a concept supported by observations that dairy goat bucks used for out-of-season matings with light-treated does also require light treatment to ensure adequate libido (Ashbrook, 1982).

Photoperiod and the female effect. The effects of photoperiod on the female effect are less clear cut than those for the male effect. Reasons for this probably include a lower level of photoperiodic inhibition of responsiveness in males (see above) and the wider use of a standardized stimulus, namely females in induced oestrus. Price et al. (1994) showed that the sexual performance of rams is not affected by the mode of induction of oestrus in intact or ovariectomized ewes, although it is not known whether this is true for the endocrine response to ewes. In sheep, the greatest response to females is observed in rams during the non-breeding season or when LH pulse frequencies are low (Schanbacher et al., 1987; Gonzalez et al., 1988a), but significant responses can occur during the breeding season (Gonzalez et al., 1988b). In pygmy goat bucks, Howland et al, (1985) found that the responses in LH, FSH and testosterone evoked by oestrous females were maximal in summer, absent 

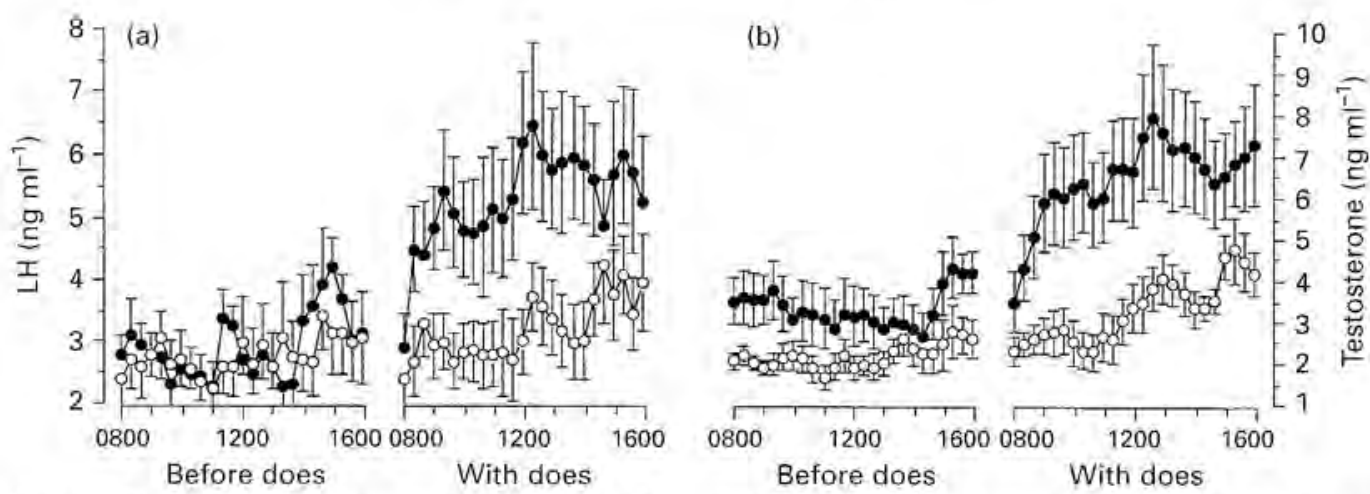

Fig. 6. Effect of oestrous does and diet on mean plasma (a) LH and (b) testosterone concentrations in mature Australian cashmere bucks fed either a low quality diet of pasture hay $(0, n=6$ or a high quality diet of pelleted lucerne $(-n=6)$ ad libitum for 16 months. Blood samples were collected at intervals of 20 min between 08.00 and $16.00 \mathrm{~h}$ on subsequent days. A doe in oestrus was introduced into each buck pen after the $08.00 \mathrm{~h}$ blood sample and was left with the buck until blood sampling ceased. Data for all sampling periods are pooled. Note that an overall effect of diet on LH and testosterone concentration is evident only during exposure to oestrous females (Walkden-Brown et al., 1994a).

during the autumn rut, and small during winter and spring. Australian cashmere bucks exhibit maximal LH and testosterone responses in summer; responses are also evident in autumn and early winter, but not late winter and spring (Walkden-Brown et al., 1994a).

\section{Nutrition}

Nutrition is a powerful regulator of reproductive function, but in seasonal breeds of sheep and goat its major effects are on ovulation rate, sperm production and the timing of the pubertal and post-partum transitions. There is little evidence that short-term changes in the nutritional status of females greatly influence their responsiveness to males during seasonal anoestrus (Kright et al., 1983b; Fisher et al., 1993a). However, longer term differences in nutrition may induce differences in the proportion of ewes ovulating during seasonal anoestrus and this in turn may be reflected in altered responsiveness to rams (Fisher et al., 1993a).

In contrast to females, short-term improvements in nutrition in males may induce rapid endocrine and testicular responses (review: Martin and Walkden-Brown, 1995) and these may allow a greater LH response to oestrous ewes (Fisher ef al., 1993b). In Australian cashmere goat bucks, longer term improvements in nutrition increased the LH and testosterone response to oestrous females (Fig. 6), but in a seasonally dependent way (Walkden-Brown et al., 1994a). Strong links between the male and female effects were revealed when bucks from this experiment, after 16 months on diets of high and low quality, were placed with does in deep seasonal anoestrus for 10 days. Bucks from the high diet induced more does to ovulate, exhibit oestrus and conceive, than did bucks on the low diet (Walkden-Brown et al., 1993a). The female responses were correlated positively with the serving capacity of the bucks and their testosterone response to oestrous does. In a similar experiment using Merino rams, 19 weeks of differential nutrition did not affect their ability to induce ovulation in late spring, and there was no association between the ovulatory response and male serving capacity (Fisher et al., 1994).

\section{Conclusion}

Under optimal conditions, interaction of males with anovulatory but responsive females initiates a self-reinforcing cycle of stimulation that culminates in the synchronous onset of fertile reproductive 


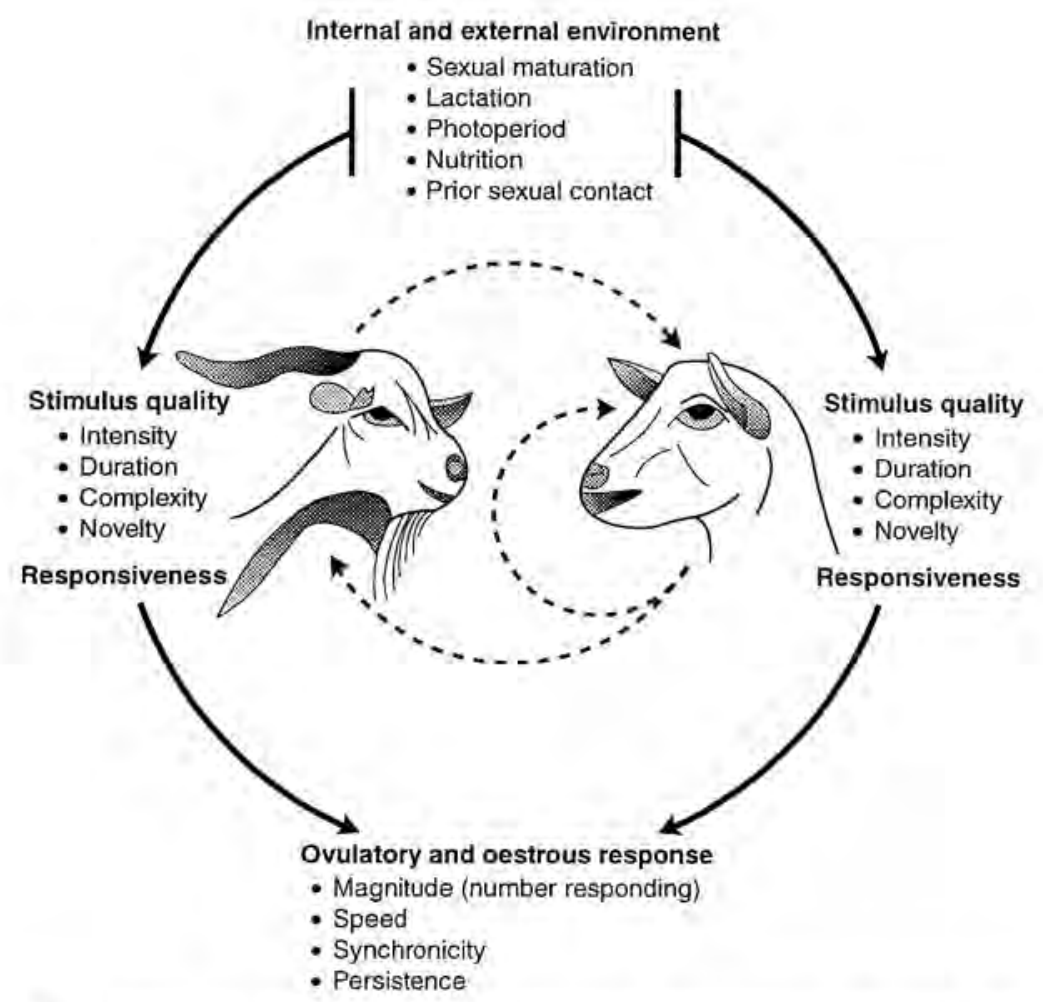

Fig. 7. Schematic representation of male-female interaction in the goat and sheep. Note the self-reinforcing cycle of stimulation that can be initiated by either sex, and which includes female-female stimulation (absent in sheep). A range of factors act on stimulus quality and responsiveness of both males and females to determine the magnitude and persistence of the oulcome. Adapted from Walkden-Brown et $a l .(1993 \mathrm{c})$.

activity (Fig. 7). Because this transition can occur so rapidly, it represents a truly opportunistic reproductive response. However, the major metabolic consequences of reproduction in sheep and goats do not occur until 4-6 months after conception, that is late gestation and early lactation, so such opportunism is tempered to limit the extent of inappropriate conception. Thus, the extent to which male-female interaction succeeds in inducing fertile reproductive activity is constrained by a range of interacting factors, particularly by photoperiod and more particularly in females (Fig. 7). This results in a wide range of possible outcomes following the initial stimulation, including termination of the response following ovulation, possibly providing a late escape from an inappropriate opportunistic pregnancy.

In the wild, social facilitation of reproduction probably operates as a means of ensuring synchronous parturition at an appropriate time and, in the longer term, as a means of varying the extent of photoresponsiveness in populations, with less photoresponsive animals continually testing the consequences of advancing the breeding season. This is consistent with the observation that breeding for reduced seasonality advances the onset of the breeding season to a much greater extent than it extends the end of the breeding season. Whether the onset of the breeding season in wild sheep and goats is triggered by a waft of male pheromones or the spontaneous onset of oestrus in a single female genetic outlier is a moot point, although the observation that the breeding season commences earlier in large herds of goats than small herds (Corteel, 1977; Shelton, 1978) lends some credence to the latter. 
In domestic sheep and goats, the male effect is a valuable tool for advancing the breeding season of seasonal breeds and for low cost synchronization of reproduction in anovulatory ewes and does. Although some of the variability in response can be removed by appropriate timing of joining, and pretreatment of females with progesterone, our understanding of the importance of the male stimulus has increased in recent years and there is good scope for extending the period during which the male effect can be reliably used by maximizing and standardizing the male stimulus through use of improved male nutrition, exposure of males to oestrous females or use of testosterone-treated castrates.

\section{References}

Amoah EA and Byrant MJ (1984) A note on the effect of contact with male goats on the occurrence of puberty in female goat kids Animal Production 38 141-144.

Ashbrook PF (1982) Year round breeding for uniform milk production. In Proceedings of the Third International Conference on Goat Production and Disease Tiscon, Arizona) pp 153-154 International Goat Association, Rutland, MD

Birch EJ, Knight TW and Shaw GJ (1989) Separation of male goat pheromones responsible for stimulating ovulatory activity in ewes New Zealand fournal of Agricultural Research 32 $337-341$

Blissitt MJ, Bland KP and Cottrell DF (1990) Olfactory and vomeronasal chemoreception and the discrimination of oestrous and non-oestrous ewe urine odours by the ram Applied Animal Behaviour Science 27 325-335

Borg KE, Esbenshade KL, Johnson BH, Lunstra DD and Ford JJ (1992) Effects of sexual experience, season and mating stimuli on endocrine concentrations in the adult ram Hormones and Behaviour 26 87-109

Cameron AWN and Batt PA (1989) The effect of continuous or sudden infroduction of bucks on the onset of the breeding season in female goats Procedings of the Anstralian Society for Reproductive Biology 21109 (Abstract)

Chemineau P (1983) Effect on oestrus and ovulation of exposing Creole goats to the male at three times of the year Journal of Reproduction and Fertility 67 65-72

Chemineau P (1987) Possibilities for using bucks to stimulate ovarian and oestrous cycles in anovulatory goats - a review Livestock Productiont Science 17 135-147

Chemineau P, Normant E, Ravault JP and Thimonier J (1986a) Induction and persistence of pituitary and ovarian activity in the out of season lactating dairy goat after a treatment combining a skeleton photoperiod melatonin and the male effect fournal of Reproduction and Feritility 78 497-504

Chemineau P, Levy F and Thimonier J (1986b) Effects of anosmia on LH secretion ovulation and oestrous behaviour induced by males in the anovular Creole goat Animat Reproduction Science 10 125-132

Claus R, Over R and Dehnhard M (1990) Effect of male odour on LH secretion and the induction of ovulation in seasonally anoestrous goats Animal Reproduction Science 22 27-38

Cognié Y, Gray SJ, Lindsay DR, Oldham CM, Pearce DT and Signoret JP (1982) A new approach to controlled breeding in the sheep using the 'ram effect' Animal Production in Australia 14 519-522

Cohen-Tannoudji J and Signoret JP (1987) Effect of short exposure to the ram on later reactivity of anoestrous ewes to the male effect Animal Reproduction Science 13 263-268

Cohen-Tannoudji J, Locatelli A and Signoret JP (1986) Non pheromonal stimulation by the male of $\mathrm{LH}$ release in the anoestrus ewe Physiology and Behatiour 36 921-924
Corteel JM (1977) Management of artificial insemination of dairy goats through oestrus synchronization and early pregnancy diagnosis. In Proceedings of the Sheep Industry Development Conference pp 1-20 Ed. C. Terrill, University of Wisconsin

Cushwa WT, Bradford GE, Stabenfeldt GH, Berger YM and Dally MR (1992) Ram influence on ovarian and sexual activity in anoestrous ewes: effects of isolation of ewes before joining and date of ram introduction Journal of Animal Science 70 1195-1200

Fisher JF, Martin GB, Oldham C and Gray S (1993a) Long term effects of nutrition on spontaneous ovulation in Merino ewes and their responses to the 'ram effect' Proceedings of the VII World Conference on Animal Production University of Alberta, Edmonton Alberta Vol. 2 Short Papers and Abstracts pp 32-33

Fisher JF, Martin GB, Hughes P, Bouckhliq R and Gray S (1993b) Nutritional effects on luteinizing hormone (LH) secretion in rams after exposure to oestous ewes Proceedings of the Australian Society for Reproductive Biology 257 (Abstract)

Fisher JF, Martin GB, Oldham C and Shepherd K (1994) Do differences in nutrition or serving capacity affect the ability of rams to elicit the 'ram effect'? Animal Production in Australio 20426 (Abstract)

Fulkerson WJ, Adams NR and Gherardi PB (1981) Ability of castrate male sheep treated with oestrogen or testosterone to induce and defect oestrus in ewes Applied Animal Ethology 7 57-66

Geytenbeek PE, Oldham CM and Gray SJ (1984) The induction of ovulation in the postpartum ewe Animal Production in Australia 15 $353-356$

Gonzalez R, Orgeur P and Signoret JP (1988a) Luteinizing hormone testosterone and cortisol responses in rams upon presentation of estrous females in the non-breeding season Theriogenology 30 1075-1086

Gonzalez R, Poindron P and Signoret JP (1988b) Temporal variation in $\mathrm{LH}$ and testosterone responses of rams after the introduction of oestrous females during the breeding season lournal of Reproduction and Fertility 83 201-208

Gonzalez R, Orgeur P, Poindron P and Signoret JP (1991a) Female effect in sheep 1. The effects of sexual receptivity of fernales and the sexual experience of rams Reproduction. Nutrition Développentent 31 97-102

Gonzalez R, Levy F, Orgeur P, Poindron P and Signoret JP (1991b) Female effect in sheep 2. Role of volatile substances from the sexually receptive female; implication of the sense of smell Reproduction, Nutrition Développement 31 103-109

Hamada T, Nakajima M, Takeuchi Y and Mori Y (1996) Pheromoneinduced stimulation of hypothalamic gonadotropinreleasing hormone pulse generator in ovariectomized estrogen-primed goats Neuroendocrinology 64 313-319 
Hillbrick GC and Tucker DJ (1996) Effect of nutrition on lipid production and composition of cashmere buck fleece Small Ruminant Research 22 225-230

Hillbrick GC, Tucker DJ and Smith GC (1995) The lipid composition of cashmere goat fleece Australian Joumal of Agricultural Resenirch 46 1259-1271

Howland BE Sanford LM and Palmer WM (1985) Changes in the serum levels of LH, FSH, prolactin, testosterone and cortisol associated with season and mating in male pygmy goats Journal of Andrology 6 89-96

Jenkinson DM, Blackburn PS and Proudfoot R (1967) Seasonal changes in the skin glands of the goat British Veteriuary journal 123541-549

Knight TW (1985) Are rams necessary for the stimulation of anoestrus ewes with oestrus ewes? Proceedings of flic New Zealand Society for Animal Production 45 49-50

Knight TW and Lynch PR (1980) Source of ram pheromones that stimulate ovulation in ewes Animal Reproduction Science 3 133-136

Knight TW, Tervit HR and Lynch PR (1983a) Effects of boar pheromones, rams wool and presence of bucks on ovarian activity in anovular ewes early in the breeding season Animal Reproduction Science 6 129-134

Knight TW, Hall DRH and Wilson LD (1983b) Effects of teasing and nutrition on the duration of the breeding season in Romney ewes Proceedings of the New Zenland Sociefy of Animal Production 43 17-19

Lindsay DR and Signoret JP (1980) Influence of behaviour on reproduction Proceedings of the 9th Intemational Congress on Animal Reproduction and Artificial Insentination, Madrid 1 83-92

Lishman AW (1969) The seasonal pattern of oestrus amongst ewes as affected by isolation from and joining with rams Agroanimalia 195-102

Martin GB and Scaramuzzi RJ (1983) The induction of oestrus and ovulation in seasonally anovular ewes by exposure to rams Journal of Steroid Biochemistry 19.869-875

Martin GB and Walkden-Brown SW (1995) Nutritional influences on reproduction in mature male sheep and goats Journal of Reproduction and Fertility Supplement 49 437-449

Martin GB, Oldham CM, Cognie $Y$ and Pearce DT (1986) The physiological responses of anovulatory ewes to the introduction of rams - a review Livestock Production Science 15 219-247

Martin ICA, Lapwood KR and Elgar HJ (1984) Changes in plasma concentrations of cortisol and prolactin in rams associated with ejaculation of semen. In Reproduction in Sheep pp 86-88 Eds DR Lindsay and DT Pearce, Australian Academy of Science, Canberra

Mattner PE and Braden AWH (1975) Studies in the flock mating of sheep 6 . Influence of age hormone treatment shearing and diet on the libido of Merino rams Australian lourial of Experimental Agriculture and Aniunal Husbandry 15330-336

Morgan PD, Arnold GW and Lindsay DR (1972) $A$ note on the mating behaviour of ewes with various senses impaired Journal of Reproduction and Ferfility 30151-152

Murtagh JJ, Gray SJ, Lindsay DR, Oldham CM and Pearce DT (1984a) The effect of the presence of rams on the continuity of ovarian activity of maiden merino ewes in spring. In Reproduction in Sheep pP 37-38 Eds DR Lindsay and DT Pearce. Australian Academy of Science, Canberra

Murtagh JJ, Gray SJ, Lindsay DR and Oldham CM (1984b) The influence of the 'ram effect' in 10-1-month-old Merino ewes on their subsequent performance when introduced to rams again at 15 months of age Anininl Production in Australia $15490-493$

Notter DR (1989) Effects of continuous ram exposure and early spring lambing on initiation of the breeding season in yearling crossbred ewes Animal Reproduction Science 19 265-272

Oldham CM, Martin GB and Knight TW (1978) Stimulation of seasonally anovular Merino ewes by rams. I Tïme from introduction of the rams to the preovulatory LH surge and ovulation Animal Reproduction Science 1 283-290

Ortavant R, Bocquier F, Pelletier J, Ravault JP, Thimonier J and Volland-Nail P (1988) Seasonality of reproduction in sheep and its control by photoperiod Australian fournal of Biological Science 41 69-85

Pearce GP and Oldham CM (1988) Importance of non-olfactory ram stimuli in mediating ram-induced ovulation in the ewe Joumal of Reproduction and Ferfility 84 333-339

Perkins A and Fitzgerald JA (1992) Luteinizing hormone testosterone and behavioral response of male-oriented rams to estrous ewes and rams fournal of Animal Science 70 $1787-1794$

Perkins A and Fitzgerald JA (1994) The behavioural component of the ram effect: the influence of ram sexual behayior on the induction of estrus in anovulatory ewes joumal of Animal Science 72 51-55

Price EO, Blackshaw JK, Blackshaw A, Borgwardt R, Dally MR and Bondurant RH (1994) Sexual responses of rams to ovariectomised and intact estrous ewes Applied Animal Behaviour Science 42 67-71

Restall BJ (1992) Seasonal variation in reproductive activity in Australian goats Animal Reproduction Science 27 305-318

Restall BJ, Restall $\mathrm{H}$ and Walkden-Brown SW (1995) The induction of ovulation in anovulatory goats by oestrous females Animal Reproduction Science 40 299-303

Riches JH and Watson RH (1954) The influence of the introduction of rams on the incidence of oestrus in Merino ewes Australian Journal of Agricultural Research 5 141-147

Sanford LM Palmer WM and Howland BE (1974) Influence of sexual activity on serum levels of $\mathrm{LH}$ and testosterone in the ram Canadian jowrnal of Animal Science 54 579-585

Schanbacher BD, Orgeur P, Pelletier J and Signoret JP (1987) Behavioural and hormonal responses of sexuallyexperienced lle-de-France rams to oestrous females Animal Reproduction Science 14 293-300

Shackelton DM and Shank CC (1984) A review of the social behavior of feral and wild sheep and goats journal of Animal Science 58 500-509

Shelton M (1960) The influence of the presence of the male on initiation of oestrus cycling and ovulation in Angora does Journal of Animal Scionce 19 368-375

Shelton M (1978) Reproduction and breeding of goats lournal of Dairy Science $61994-1010$

Shelton M (1980) Goats: influence of various exteroceptive factors on initiation of estrus and ovulation International Goat and Slieep Reseârch 1 156-162

Signoret JP (1991) Sexual pheromones in the domestic sheep: importance and limits in the regulation of reproductive physiology Journal of Steroid Biochemistry and Molecular Biology 39 639-645

Signoret JP, Fulkerson W] and Lindsay DR (1982) Effectiveness of testosterone treated wethers and ewes as teasers Applied Animal Ethology 9 37-45

Sugiyama T, Matsuura H, Sasada H, Masaki J and Yamashita $\mathrm{K}$ 
(1986) Characterization of fatty acids in the sebum of goats according to sex and age Agricultural Biology and Chemistry $503049-3052$

Thiéry JC and Signoret JP (1978) Effect of changing the teaser ewe on the sexual activity of the ram Applied Animal Ethology 4 31-34

Walkden-Brown SW and Restall BJ (1996) Environmental and social factors affecting reproduction. In Proceedings of the VI International Conference on Gonts (Beijing, 1996) Vol. 2 pp 762-775 Ed. PJ Host. Inlernational Academic Publishers, Beijing

Walkden-Brown SW, Restall BJ and Henniawati (1993a) The male effect in Australian cashmere goats 3 . Enhancement with buck nutrition and use of oestrous females Animal Reproduction Science 32 69-84

Walkden-Brown SW, Restall BJ and Henniawati (1993b) The male effect in Australian cashmere goats 2. Role of olfactory cues from the male Animal Reproduction Science 32 55-67

Walkden-Brown SW, Restall BJ and Henniawati (1993c) The male effect in Australian cashmere goats 1. Ovarian and behavioural response of seasonally anovulatory does following the introduction of bucks Animal Reproduction Science 32 41-53

Walkden-Brown SW, Boukhliq R, Fisher JS and Martin GB (1993d) Does the nutrition of the ram influence its behavioural and endocrine response to oestrous ewes? Proceedings of the Australian Society for Reproductive Biology 2538 (Abstract)

Walkden-Brown SW, Restall BJ, Norton BW and Scaramuzzi RJ (1994a) The 'female effect' in Australian cashmere goats. Effect of season and diet quality on the L.H and testosterone response of bucks to oestrous does Journal of Reproduction and Fertility $100521-531$

Walkden-Brown SW, Restall BJ, Norton BW, Scaramuzzi RJ and Martin GB (1994b) Effect of nutrition on seasonal patterns of $\mathrm{LH}, \mathrm{FSH}$ and testosterone concentration testicular mass, sebaceous gland volume and odour in Australian cashmere goats Journal of Reproduction and Fertility 102 351-360

Wright PJ Geytenbeek PE and Clarke IJ (1990) The influence of nutrient status of post-partum ewes on ovarian cyclicity and on the oestrous and ovulatory responses to ram introduction Animal Reproduction Science 23 293-303 